\title{
AVALIAÇÃO DE EFICIÊNCIA DE ESTRATÉGIAS DE HEDGE PARA O RISCO DE PREÇO DO CAFÉ DO BRASIL COM O USO DE CONTRATOS DA BM\&FBOVESPA
}

\section{EVALUATION OF HEDGING STRATEGIES EFFECTIVENESS FOR COFFEE PRICE RISK IN BRAZIL WITH THE USE OF BM\&FBOVESPA CONTRACTS}

\author{
Data de submissão: $26 / 02 / 2014$ \\ Aceite: 20/05/2016 \\ Waldemar Antonio da Rocha de Souza ${ }^{1}$ \\ André Ricardo Reis Costa² \\ Tristão Sócrates Baptista Cavalcante ${ }^{3}$ \\ Claudio Zancan ${ }^{4}$ \\ Pedro Valentim Marques ${ }^{5}$
}

\section{RESUMO}

O Brasil é o maior produtor e exportador mundial de café. Entretanto o novo regime de preços e volatilidade a partir da crise de 2008, bem como o aumento da concorrência pela entrada de novos players expressaram a necessidade de uso de mecanismos de mercado para gestão de risco de preço. Entre as alternativas, ilustravam-se os mercados futuros, em particular os contratos futuros de café da BM\&FBOVESPA, do Brasil. Objetivou-se avaliar a eficiência das estratégias sem hedge, hedge simples (naïve), hedge estático e hedge dinâmico calculado pelo modelo GARCH-BEKK na gestão de risco dos preços do café das principais regiões produtoras brasileiras. A eficiência dos hedges estático e dinâmico foi superior à das outras estratégias, embora o último possibilite a calibragem das taxas de hedge intertemporais, diminuindo os custos operacionais. Também, o uso dos contratos futuros de café da BM\&FBOVESPA para hedge aumentará a liquidez do mercado, possibilitando a esquematização de várias alternativas operacionais.

Palavras-chave: Café; Estratégias de hedge; Eficiência; BM\&FBOVESPA.

\footnotetext{
1 Possui Graduação em Economia pela Universidade Federal do Amazonas, UFAM. Mestrado em Economia pela Fundação Getúlio Vargas, FGV. Doutorado em Ciências (Economia Aplicada) pela Universidade de São Paulo, USP. Maceió. Alagoas. Brasil. E-mail: warsouza@ufam.edu.br 2 Possui Graduação em Ciências Contábeis pela Universidade Federal do Amazonas, UFAM. Mestrado em Contabilidade e Controladoria pela Universidade Federal do Amazonas, UFAM. Atualmente é Doutorando em Administração pela Universidade de São Paulo e Professor Assistente do Departamento de Contabilidade da Universidade Federal do Amazonas. Manaus. Amazônia. Brasil. E-mail: andrecosta@ufam.edu.br

3 Possui Graduação em Ciências Econômicas e Administração pela Universidade Federal do Amazonas - UFAM. Especialização em Engenharia Econômica e MBA em Gestão de Insituição de Ensino pelo Centro Universitário do Norte - UNINORTE (2007). Mestrado em Engenharia da Produção pela Universidade Federal de Santa Catarina - UFSC. Mestrado em Economía y Empresa - Univesitat de Les Illes Balears. Doutorado em Engenharia da Produção pela Universidade Federal de Santa Catarina - UFSC. Atualmente cursando Pós-Doutorado em Administração na Universidade Federal de Minas Gerais pesquisando Custos na área da sáude. Atualmente professor concursado da Universidade Federal do Amazonas. Manaus. Amazônia. Brasil. E-mail: tristaosbc@gmail.com

4 Possui Graduação em Ciências Contábeis. Especialização em Marketing e em Comércio Exterior. Mestrado em Administração na linha de pesquisa Marketing Industrial. Doutorado em Administração na linha de pesquisa Inovação e Redes de Cooperação Interorganizacional. Atualmente é Professor Adjunto vinculado a Faculdade de Ecomomia, Administração e Contabilidade na Universidade Federal de Alagoas. A linha de pesquisa é sobre Redes de Cooperação Interorganizacional e Inovação. Maceió. Alagoas. Brasil. E-mail: claudiozancan@gmail.com

5 Possui graduação em Engenharia Agronômica pela Universidade de São Paulo. Mestrado em Economia e Sociologia Rural pela Escola Superior de Agricultura Luiz de Queiroz Esalq. Doutorado em Economia Agrícola - University Of Kentucky. Atualmente é Professor Titular da Universidade de São Paulo. Atua na área de Economia com ênfase mercados futuros agropecuários, agribusiness, agronegócios, descobrimento de preços e organização de mercados agroindustriais. Piracicaba. São Paulo. Brasil. E-mail: pvmarque@usp.br
} 


\begin{abstract}
Brazil is the world's largest coffee producer and exporter. However the new prices and volatility scenario since the 2008 crisis and the increasing competition of new players entry have expressed the need for use of market mechanisms for managing price risk. Among the alternatives illustrated are the futures markets, in particular the coffee futures contracts at BM\&FBOVESPA, Brazil. Our aim was to evaluate the efficiency of no hedge, simple (naïve) hedge, static and dynamic hedge calculated by GARCH-BEKK strategies in managing price risk in the leading Brazilian coffee producing regions. The efficiencies of static and dynamic hedging strategies were superior to the other, although the latter allows the calibration of intertemporal hedging rates, reducing operational costs. Also, the use of BM\&FBOVESPA coffee futures contracts for hedging might increase market liquidity, enabling various operational alternatives design.
\end{abstract}

Keywords: Coffee; Hedging strategies; Efficiency; BM\&FBOVESPA.

\title{
1 INTRODUÇÃO
}

Os mercados futuros agropecuários arrolam uma alternativa para mensurar e administrar eficientemente o risco de preços das commodities brasileiras. Identificam-se, por exemplo, o aumento do risco dos preços agropecuários pelos recentes níveis absolutos e a volatilidade de preços de commodities após a crise financeira do subprime de 2008 (EUROPEAN COMMISSION, 2009). O novo regime de níveis e volatilidade de preços agropecuários nos mercados internacionais ilustra a necessidade de mitigação de riscos eficientemente, classificando-se como mecanismos potenciais os contratos futuros e de opções, brasileiros e internacionais.

Como exemplo, os mercados futuros podem ser usados em várias engenharias para o auxílio na descoberta de preços, a melhoria da gestão de risco, a facilitação para medir e captar capital de giro adicional e o fornecimento de fontes de informações para a tomada de decisões (LEUTHOLD; JUNKUS; CORDIER, 1989).

Contudo, em comparação com grandes players internacionais, como, por exemplo, os Estados Unidos, a China e a Argentina, o uso dos mercados futuros agropecuários no Brasil ainda aponta volumes baixos. Apontaram-se os volumes diários, os contratos negociados, os contratos em aberto e o giro financeiro dos contratos futuros das principais commodities agropecuárias brasileiras inferiores aos contratos similares negociados nas bolsas de futuros e de opções dos países (LEÃO et al., 2013). O registro pode descrever a subutilização de um eficiente mecanismo de mercado para mitigar os riscos de preço, possibilitando esquematizar engenharias financeiras para as fases e necessidades dos agentes das cadeias agropecuárias brasileiras.

Em particular, destaca-se a produção de café brasileira: o Brasil é o maior produtor mundial, totalizando cerca de 49,2 milhões de sacas produzidas, aproximadamente $37 \%$ do total mundial, em 2011. Em adição, as exportações de café registraram cerca de US\$ 8,7 bilhões, equivalentes a 9,2\% do total exportado pelo agronegócio doméstico, com market-share de 28,3\% das exportações totais mundiais no período (USDA, 2011; MAPA, 2012). Em adição, a cultura do café articulou um fator relevante para a evolução econômica do país (DELFIM NETO, 1973; BACHA, 1992).

Porém, pesquisas identificaram o aumento da concorrência internacional no mercado de café, destacando o crescimento da participação do Vietnã, impactando a posição do Brasil (NISHIJIMA; SAES; POSTALI, 2012). Também, os mercados à vista de café traduziram forte variabilidade de preços e quantidade produzida, com elevados riscos para os países produtores (OUATTARA; SCHROEDER; SORENSON, 1990).

Assim, enunciam-se as condições para o uso de instrumentos eficientes de administração de risco dos preços do café do Brasil, destacadamente os contratos futuros de café da 
BM\&FBOVESPA. Em adição, os contratos futuros de café podem ser usados pelos produtores e processadores em estratégias de hedge de risco de preço, bem como para a descoberta de preços e previsão de volatilidade futura. Os resultados podem ser empregados nas fases da cadeia de oferta da commodity, como, por exemplo, no processo de previsão de preços, na calibração das taxas de hedge, nas projeções de fluxo de caixa, na administração de estoques e nas decisões de alavancagem financeira e comercialização.

Portanto, a questão de pesquisa deste estudo é avaliar a eficiência das estratégias de hedge do risco de preço do café do Brasil, nas regiões de Mogiana (SP), Planalto (SP), Cerrado (MG), Sul de Minas (MG), Zona da Mata (MG) e Noroeste (PR) com o uso dos contratos futuros da BM\&FBOVESPA.

Em termos específicos, objetiva-se calcular as taxas de hedge do risco de preço do café do Brasil com o uso de contratos futuros da BM\&FBOVESPA, aplicando as estratégias sem hedge, hedge simples (naïve), hedge estático e hedge dinâmico. A seguir, comparar os resultados para identificar a estratégia de hedge mais eficiente para mitigar o risco de preço do café das diferentes regiões produtoras brasileiras. Os resultados podem ser aplicados em decisões dos agentes da cadeia de oferta de café nas diversas regiões produtoras do Brasil.

$\mathrm{O}$ trabalho divide-se em quatro seções. A próxima seção registra a revisão de literatura. A seguir, explicam-se a metodologia e os dados usados. A seção seguinte registra os resultados e discussão. Por último, resumem-se as principais conclusões do estudo.

\section{REVISÃO DE LITERATURA}

Dada a importância do hedge para os mercados futuros, diversos pesquisadores acadêmicos e práticos demonstraram interesse no tema. Adicionalmente, um foco relevante das pesquisas é a determinação da taxa ótima de hedge, existindo vários modelos explicativos. Registram-se o hedge de mínima variância, a avaliação de risco e retorno esperado do portfólio com hedge e os modelos de hedge dinâmico, entre os principais (CHEN; LEE; SHRESTHA, 2003).

Johnson (1960) destacou que a efetividade do hedge seria mais elevada, quanto maior fosse a correlação subjetiva dos preços à vista e futuros. Adicionalmente, o hedge puro seria uma combinação de posição à vista, com expectativa de lucratividade, e futura, para minimizar o risco dos preços à vista.

Stein (1961), aplicando o arcabouço de média-variância, formulou uma técnica para a determinação simultânea dos preços à vista e futuros de commodities, explicando os estoques com hedge e a fração sem hedge. Registrou que os fatores determinantes para hedge eram as variações dos preços à vista e futuros resultantes do excesso de oferta da produção do período atual e variações das expectativas dos preços.

Collins (1997) comparou o comportamento previsto nos modelos com a evidência das operações de hedge. Concluiu que a evidência apontava para o hedge simples por parte dos arbitrantes e intermediários e o hedge parcial pelos processadores, enquanto os produtores raramente usavam hedge.

Por sua vez, Ederington (1979) formulou modelo para o hedge ótimo, a partir da diferença entre os preços à vista e futuros, usando o arcabouço de média-variância. Dessa forma, a taxa de hedge ótimo, de variância mínima num portfólio sintético bivariado com posições à vista e futura, poderia ser calculada pela minimização da variância total do portfólio em relação ao quociente de hedge. Estimou que um produtor de trigo que mantivesse $74 \%$ do estoque com hedge reduziria o risco de preço em $84 \%$.

Também, destaca-se que Karp (1987) foi o primeiro autor a avaliar o hedge ótimo para commodities agropecuárias sob condições dinâmicas, incluindo a incerteza da produção, aplicando a teoria de controle. Concluiu que o hedge dinâmico era mais eficiente do que o hedge de variância mínima. 
Por seu turno, Myers e Thompson (1989) esquematizaram um arcabouço generalizado para estimação da taxa de hedge ótimo, apontando técnicas de mínimos quadrados ordinários em única equação. Adicionalmente, exemplificaram com o hedge de milho, soja e trigo, apontando que as regressões nos níveis dos preços eram inadequadas, enquanto a regressão simples nas primeiras diferenças resultava em valores próximos ao modelo generalizado. A pesquisa sancionou em definitivo o uso de primeiras diferenças como o método mais eficiente e útil para o cálculo da taxa de hedge ótimo.

Baillie e Myers (1991) examinaram a distribuição dos preços à vista e futuros para seis commodities, calculando a taxa de hedge ótimo com o uso de modelo GARCH (Generalized Autoregressive Conditional Heteroskedasticity) bivariado, aplicando as estimativas da matriz de covariância condicional dinâmica no tempo entre os preços à vista e futuros. Assim, as taxas de hedge ótimo variavam no tempo. A eficiência do hedge dinâmico foi maior, em termos de redução da variância dos portfólios sintéticos com posições à vista e futuras.

Também usando modelagem GARCH, Kroner e Sultan (1993) calcularam as taxas de hedge dinâmico e convencional para portfólios com risco cambial, incluindo os custos de transação. Concluíram que o hedge dinâmico apresentava efetividade superior às demais estratégias de hedge, apontada pela redução da variância total do portfólio, apesar da inclusão dos custos transacionais.

Moschini e Myers (2002) compararam os modelos de hedge de mínima variância e dinâmico calculado pela metodologia GARCH-BEKK para o risco de preço do milho de lowa (EUA), num horizonte semanal. Identificaram que o hedge ótimo dinâmico era mais eficiente, uma vez que incorporava a dinâmica temporal dos preços, a qual não poderia ser explicada apenas pelos efeitos de sazonalidade e vencimento.

Por seu turno, Lien e Yang (2008) examinaram os efeitos do comportamento assimétrico da base sobre a estrutura de variâncias e correlações dos preços à vista e futuros de dez commodities, analisando os impactos sobre o hedge dinâmico. Aplicando modelagem BGARCH para o cálculo dos quocientes de hedge dinâmico ótimo, registraram que o impacto da base positiva era maior do que o da negativa e a incorporação do efeito assimétrico da base aumentava a eficiência do hedge.

Também, Chang, McAleer e Tansuchat (2011) compararam a efetividade de hedge dos modelos dinâmicos da família GARCH, CCC, VARMA-GARCH, DCC, BEKK e BEKK diagonal, para portfólios com posições combinadas nos mercados à vista e futuros de petróleo. Concluíram que os resultados de efetividade de hedge variavam por tipo de modelo e mercado analisado, com os resultados mais baixos calculados pelo modelo BEKK diagonal.

Shi e Irwin (2005) desenvolveram um modelo empírico de hedge ótimo bayesiano, que apontava a estimação paramétrica de risco num arcabouço teórico e quantitativo para examinar as avaliações subjetivas com consensos individuais e de mercado para calcular a taxa de hedge ótimo. Aplicou-se a modelagem bayesiana ao milho, resultando em flexibilidade do número e do tipo de óticas subjetivas.

De forma análoga, Bitencourt, Silva e Sáfadi (2006) compararam os modelos de variância mínima e GARCH-BEKK bivariado para o boi gordo no Brasil. Concluíram que a taxa de hedge ótimo variava no tempo, apontando que o uso dos modelos dinâmicos resultou numa efetividade de hedge superior. Lazzarini (2010) avaliou modelos de hedge dinâmico para boi gordo, incluindo os períodos de safra e entressafra. Concluiu que o modelo de correlação condicional dinâmica (DCC) apontou a melhor efetividade e que a taxa de hedge ótimo na entressafra não era superior à da safra.

Silveira (2002) avaliou o hedge próprio para boi gordo e cross-hedge entre bezerro e boi gordo em São Paulo, com o uso de contratos futuros da BM\&FBOVESPA, aplicando a metodologia de Myers e Thompson (1989). Concluiu que as taxas de hedge ótimo eram elevadas, entretanto a efetividade do cross-hedge foi baixa, enquanto o hedge próprio apresentou efetividade em torno de $50 \%$. 
Rosalem, Gomes e Oliveira (2008) analisaram o comportamento da base em cinco regiões criadoras de boi gordo no Brasil, relativamente aos contratos futuros da BM\&FBOVESPA com diferentes vencimentos. Destacaram períodos ideais para operar o hedge estático de compra e venda.

Em adição, Souza, Martines-Filho e Marques (2011) avaliaram a estratégia de hedge simultâneo do risco de preço e de câmbio para a soja do Centro-Oeste, usando contratos da BM\&FBOVESPA. Concluíram que o hedge simultâneo registrava a maior efetividade comparada ao hedge simples e hedge isolado de preços. Martins e Aguiar (2004) avaliaram a efetividade de hedge para a soja brasileira de diferentes regiões dos contratos futuros da CBOT com diferentes vencimentos. Apontaram que os contratos com vencimento no segundo semestre eram mais eficientes, em particular os de julho e agosto.

Silva, Aguiar e Lima (2003) avaliaram a efetividade de hedge para o complexo de soja brasileiro na CBOT e BM\&FBOVESPA. Concluíram que os contratos futuros de soja da BM\&FBOVESPA registravam estratégias de cross-hedge para óleo e farelo de soja com baixa eficiência. Entretanto, o hedge do óleo e farelo de soja era vantajoso usando-se os contratos análogos da CBOT. Adicionalmente, a efetividade de hedge para a soja em grão foi mais eficiente na BM\&FBOVESPA.

Maia e Aguiar (2010) avaliaram o risco e retorno de estratégias de hedge usando contratos da CBOT para as principais regiões produtoras de soja do Brasil. Concluíram que as bases apresentaram padrão bem definido, fortalecendo-se entre maio e novembro, seguido por subsequente enfraquecimento. Também, os hedgers de compra detinham oportunidades de maiores retornos brutos, porém com riscos mais elevados. Adicionalmente, apontaram que os contratos de soja da CBOT demonstraram retornos brutos diferenciados devido ao tipo de hedge, ao horizonte de hedge e ao vencimento do contrato.

Também, Souza e Caldarelli (2011) analisaram a efetividade de hedge para a soja do Centro -Oeste aplicando modelos de variância mínima e dinâmico GARCH-BEKK. Destacaram que a efetividade de hedge do modelo dinâmico foi superior, melhorando a capacidade alocativa dos agentes da cadeia de soja e possibilitando decisões mais eficientes de produção, comercialização e armazenagem.

Souza et al. (2011) estimaram o grau de eficiência do cross-hedge do risco de preços de frango usando contratos futuros de milho da BM\&FBOVESPA. Apontaram que a eficiência do cross-hedge era baixa, podendo ser atribuída à baixa correlação entre os preços devido a estruturas microeconômicas distintas, como a sazonalidade das vendas, a formação de estoques, a distribuição do ano-safra e as condições de abate do plantel de aves. Entretanto, devido à relevância econômica da indústria de frango do Brasil, seria estratégico examinar a viabilidade para implantação de um contrato futuro nacional para a commodity.

Em particular, com relação ao café, Ouattara, Schroeder e Sorenson (1990) avaliaram o hedge ótimo para o café exportado da Costa do Marfim, usando modelo de média-variância com utilidade esperada. Concluíram que os ganhos de exportação poderiam ser estabilizados com o uso de contratos futuros de café.

Mohan (2007) estimou o custo e benefício de estratégias de hedge de risco de preço de café usando opções de venda sobre contratos futuros de Londres e Nova lorque, calculando o retorno de operações com as opções. Destacou que os custos das estratégias de hedge com opções de venda eram relativamente baixos em relação aos preços, sublinhando a viabilidade das operações.

Gemech et al. (2011) avaliaram a alocação eficiente de recursos na produção de café usando contratos futuros e de opções para gerenciar o risco de preços. Apontaram que os benefícios do uso de mecanismos de mercado para mitigação de risco do preço do café eram elevados, apesar da forte aversão ao risco dos produtores. Entretanto, permanecia o desafio de disponibilizar o acesso aos mecanismos para os pequenos produtores de regiões em desenvolvimento. 
Especificamente para o café do Brasil, Fileni, Marques e Machado (1999) avaliaram o hedge de risco de preços de café em Minas Gerais, examinando o risco de base e a efetividade de hedge dos contratos futuros de café da BM\&FBOVESPA. Concluíram que o risco de base entre as principais regiões produtoras era semelhante, proporcionando significativa redução do risco de preço. Entretanto, o risco de base entre os meses foi significativamente diferente, apontando a necessidade de escolha do mês de vencimento do contrato. Adicionalmente, o hedge antecipatório registrou eficiência para um período de duração de três meses.

Harzer et al. (2012) examinaram a forma fraca de eficiência do mercado futuro brasileiro de café arábica, usando o método de cointegração, identificando se os preços futuros eram estimadores não viesados dos preços à vista esperados para o futuro. Destacaram que o mercado futuro brasileiro do café arábica apontava indícios estatísticos de não eficiência, bem como viés de existência de um prêmio de risco.

Também, Müller (2007) comparou a efetividade de estratégias de hedge para o mercado futuro de café arábica no Brasil. Concluiu que o hedge dinâmico registrou a maior efetividade, mensurada pela redução da variância dos preços.

Em particular, Pimenta et al. (2011) analisaram a estrutura cognitiva de valores de consumidores em relação a marcas regionais de café na região de Lavras (MG), usando a Cadeia de Meios-Fim, em conjunto com a técnica laddering. Concluíram que existia relação entre a marca regional e a determinação de compra. Valores pessoais registravam-se nas marcas regionais, em particular os atributos "regional", "características sensoriais", "pureza do alimento" e "preço mais baixo".

Em resumo, as pesquisas acadêmicas validam o uso dos mercados futuros para gerenciamento do risco dos preços agropecuários. Embora o risco dos preços agropecuários, as estratégias de hedge, a previsão de base e volatilidade e as operações especulativas sejam temas sistematicamente pesquisados na literatura internacional, no Brasil o conjunto de temas é inexplorado. Para o setor cafeeiro brasileiro, em especial, destacam-se poucas pesquisas aplicadas sobre as questões.

Nessa linha, a contribuição inédita do artigo é avaliar a eficiência das estratégias de hedge do risco de preço do café do Brasil, nas regiões de Mogiana (SP), Planalto (SP), Cerrado (MG), Sul de Minas (MG), Zona da Mata (MG) e Noroeste (PR) com o uso dos contratos futuros da BM\&FBOVESPA. Os resultados poderão servir como inputs estratégicos para os administradores de risco da cadeia de café do Brasil.

\section{METODOLOGIA E DADOS}

Descrevem-se as etapas metodológicas e dados usados na pesquisa, a qual se define por (BOOTH; COLOMB; WILLIAMS, 2008, p. 317):

i. quanto aos objetivos: exploratória, caracterizando uma população, fenômeno ou relações entre as variáveis com coletas de dados; delimitam-se técnicas, métodos, modelos, teorias, objetivos, termos, variáveis, hipóteses e questões de pesquisa;

ii. quanto aos procedimentos: bibliográfica e experimental, baseada em referenciais teóricos publicados em documentos, realizada independentemente ou como parte da pesquisa descritiva ou experimental, estudando variáveis independentes;

iii. abordagem da questão de pesquisa: qualitativa e quantitativa, coletando e examinando os dados para estimar o tema pesquisado. 
Assim, para apreciar os objetivos específicos, objetiva-se calcular as taxas de hedge do risco de preço do café do Brasil com o uso de contratos futuros da BM\&FBOVESPA, aplicando as estratégias sem hedge, hedge simples (naïve), hedge estático e hedge dinâmico.

A seguir, comparam-se os resultados para identificar a estratégia de hedge mais eficiente para mitigar o risco de preço do café das diferentes regiões produtoras brasileiras. Examinouse a efetividade de estratégias de hedge do risco dos preços do café do Brasil usando os contratos futuros da BM\&FBOVESPA em etapas definidas sequencialmente.

A primeira foi a construção de portfólios sintéticos bivariados com posições à vista e futuras. Na segunda, calculou-se a efetividade do hedge simples (naïve). A seguir, investigou-se a efetividade do hedge estático de variância mínima. Por último, registrou-se a efetividade do hedge dinâmico pelo modelo GARCH-BEKK, comparando-se a efetividade dos modelos de hedge avaliados.

\subsection{Construção de portfólios sintéticos com posições à vista e futuras}

Para analisar a efetividade de hedge, examinaram-se portfólios sintéticos compostos de dois ativos, a posição à vista e em contratos futuros de café. Conforme Leuthold, Junkus e Cordier (1989), o retorno esperado de um portfólio de dois ativos, com posições nos mercados à vista e futuros, pode ser expresso pela Equação 1:

$$
E\left(\widetilde{R}_{p}\right)=X_{s} E\left(\widetilde{R}_{s}\right)+X_{f} E\left(\widetilde{R}_{f}\right)
$$

Onde:

$X s=$ valor da posição à vista

$X f=$ valor da posição em futuros

$E\left(\widetilde{R}_{s}\right)=$ retorno esperado da posição à vista, ou seja, diferença entre os preços à vista no momento inicial e a data de vencimento dos contratos futuros

$E\left(\widetilde{R}_{f}\right)=$ retorno esperado da posição com contratos futuros, ou seja, diferença entre os preços futuros no momento inicial e a data de vencimento dos contratos futuros

O risco financeiro de carregamento das posições pode ser expresso como a variância total do retorno do portfólio sintético, $V\left(\widetilde{R}_{p}\right)$ :

$$
V\left(\widetilde{R}_{p}\right)=X_{s}^{2} \mathbf{s}_{s}^{2}+X_{f}^{2} s_{f}^{2}+2 X_{s} X_{f} s_{f}
$$

Onde:

$\mathrm{S}_{S_{2}}^{2}=$ variância dos retornos à vista (variação de preço)

$\mathrm{S}_{s}^{2}=$ variância dos retornos futuros (variação de preço)

$\mathrm{S}_{f}=$ covariância entre as variações dos preços à vista e futuros (retornos)

Dessa maneira, para comparar a efetividade de hedge, analisaram-se quatro portfólios. O primeiro, sem hedge, equivale a uma posição nula em contratos futuros. A variância total do retorno do portfólio sem hedge serviu de parâmetro comparativo para a avaliação dos demais modelos de hedge. 


\subsection{0 modelo de hedge simples (naïve)}

O segundo modelo, de hedge simples (naïve), corresponde a uma posição em contratos futuros para cada posição à vista, ou seja, a posição futura iguala a posição à vista, em sentido contrário, sem variação temporal, implicando em $X s=-X f=c$, na Equação 3:

$$
E\left(\widetilde{R}_{p}\right)=c\left[E\left(\widetilde{R}_{s}\right)-E\left(\widetilde{R}_{f}\right]\right.
$$

Assim, a estratégia de hedge simples (naïve) equivale à exposição exclusiva ao risco de base. Para o portfólio sintético com hedge simples (naïve), tem-se que a variância total será dada pela Equação 4:

$$
V\left(\widetilde{R}_{p}\right)=c^{2}\left[\mathrm{~s}_{s}^{2}+\mathrm{s}_{f}^{2}-2 \mathrm{~s}_{f}\right]
$$

A Equação 4 registra a variância total do portfólio sintético com hedge simples, idêntica à variância da base.

\subsection{O modelo de hedge ótimo de mínima variância estático}

Conforme Leuthold, Junkus e Cordier (1989), a partir da minimização da Equação 2 em relação a $X f$, obtém-se a taxa de hedge de risco mínimo, $X_{f}^{*}$, definida por:

$$
X_{f}^{*}=-X_{s} \frac{\mathrm{s}_{f}}{\mathrm{~s}_{f}^{2}}
$$

Expressando a Equação 5 em termos relativizados, toma-se $X s=1$ e $\beta=-X f / X s$. Assim, $\beta^{*}$, o hedge ótimo, de variância mínima, pode ser expresso como:

$$
\mathrm{b}^{*}=\frac{\mathrm{s}_{f}}{\mathrm{~s}_{f}^{2}}
$$

O valor de $\beta^{*}$ pode ser estimado pela regressão:

$$
\Delta S_{t}=\mathrm{a}+\mathrm{b} \Delta F_{t}
$$

Onde:

$S t=$ preços no mercado à vista

$F t=$ preços no mercado futuro

$\alpha, \beta=$ parâmetros a estimar

$\Delta=$ primeira diferença dos preços

Assim, o risco mínimo obtido é a variância do portfólio sintético quando $\beta=\beta^{*}$ _As Equações 6 e 7 possibilitam o cálculo do hedge de variância mínima, $\beta^{*}$, amplamente usado, de forma fácil e acessível.

Entretanto, aponta-se que $\beta^{*}$ registra um valor fixo e constante para a posição de hedge em contratos futuros, embora a estrutura de variâncias e covariâncias possa se alterar ao longo do tempo, impactando o valor do hedge ótimo, de variância mínima, dado pela Equação 6. Assim, para examinar a efetividade do hedge num contexto temporal dinâmico, aplicam-se os modelos de hedge dinâmico. 


\subsection{O modelo GARCH-BEKK de hedge ótimo de mínima variância dinâmico}

As variâncias das séries de preços agropecuários não registram valores constantes ao longo do tempo, apresentando agrupamento de volatilidades (MCKENZIE; HOLT, 2002). Portanto, qualquer estimativa realista de taxas de hedge para séries de preços agropecuários deve examinar a propriedade estatística. Assim, usou-se o teste de White (1980) nas séries de preços à vista e futuros do café do Brasil para identificar a presença de heterocedasticia, apontando o agrupamento de volatilidade dos preços.

Em seguida, para calcular as taxas de hedge num contexto temporal dinâmico, com agrupamento de volatilidade, usam-se os modelos da família GARCH. As especificações da modelagem GARCH calculam a previsão da variância condicional como uma média ponderada da variância média de longo prazo, da previsão atual e do novo conjunto informacional para o período presente capturado pelo erro quadrado mais recente (BOLLERSLEV, 1986; ENGLE, 2001).

Os modelos da família GARCH são largamente usados na literatura financeira e de preços agropecuários. Uma das abordagens mais aplicadas para cálculo de taxas de hedge dinâmico é o modelo GARCH-BEKK (ENGLE; KRONER, 1995). O modelo GARCH-BEKK é um modelo multivariado, no qual a matriz de covariâncias condicionais $\mathrm{Ht}$, dado o conjunto informacional disponível no período $t$, pode ser expressa por:

$$
\begin{aligned}
& \mathrm{e}_{t}=H_{t}^{1 / 2 \mathrm{n}_{t}} \\
& H_{t}=C^{\prime} C+\sum_{i=1}^{q} A_{i}^{\prime} \mathrm{e}_{t-1} \mathrm{e}_{t-i}^{\prime} A_{i}+\sum_{j=1}^{p} B_{j}^{\prime} H_{t-j} B_{j}
\end{aligned}
$$

Onde:

$C, A$ e $B=$ matrizes $(k \times k)$ de parâmetros, com $k=2$ no caso bivariado

$C=$ uma matriz triangular superior

$p$ e $q=$ ordens do modelo

$k=$ número de séries usadas

O modelo GARCH-BEKK possui uma particularidade na especificação, as configurações generalizadas, que permitem impactos cruzados entre as variâncias e covariâncias das variáveis, sem necessitar estimar um grande número de parâmetros, ou seja, é mais parcimonioso do que outros modelos dinâmicos da família GARCH. Assim, para o modelo GARCH-BEKK, a taxa de hedge dinâmico ótimo pode ser calculada pela Equação 10:

$$
\mathrm{b} *_{t}=\operatorname{Cov}\left(\Delta S_{t}, \Delta F_{t} \mid \Omega_{t-1}\right) / \operatorname{Var}\left(\Delta F_{t} \mid \Omega_{t-1}\right)
$$

Onde:

$\beta^{*} t=$ taxa de hedge dinâmico (ótimo)

$S=$ preços no mercado à vista

$F=$ preços no mercado futuro

$\Delta=$ primeira diferença dos preços

$\Omega_{t-1}=$ conjunto informacional no período $\mathrm{t}-1$ 
O modelo GARCH-BEKK calcula um vetor de taxas ótimas de hedge empregando a matriz de covariância condicional $\mathrm{Ht}$ :

$$
\mathrm{b}_{t}^{*}=h_{\mathrm{r}, t} / h_{2, t}
$$

Onde:

$h_{i j, t}=$ elemento da i-ésima linha e j-ésima coluna da matriz de coVaRiância condicional, Ht. Assim, num modelo bivariado, a taxa de hedge ótimo, $\beta^{*} t$, dadas as séries de preços à vista e futuros, pode ser calculada com $H t$ e a sua representação matricial será:

$$
\begin{aligned}
& {\left[\begin{array}{ll}
h_{11, t} & h_{\mathrm{L}, t} \\
h_{\mathbf{1}, t} & h_{2, t}
\end{array}\right]=\left[\begin{array}{cc}
c_{1} & 0 \\
c_{\mathbf{2}} & c_{2}
\end{array}\right]\left[\begin{array}{cc}
c_{1} & c_{\mathbf{1}} \\
0 & c_{2}
\end{array}\right]+\left[\begin{array}{ll}
a_{1} & a_{\mathfrak{1}} \\
a_{\mathbf{2}} & a_{2}
\end{array}\right]\left[\begin{array}{cc}
\mathrm{e}_{1, t-1}^{2} & \mathrm{e}_{1, t-1} \mathrm{e}_{2, t-1} \\
\mathrm{e}_{2, t-1} \mathrm{e}_{1, t-1} & \mathrm{e}_{2, t-1}^{2}
\end{array}\right]\left[\begin{array}{ll}
a_{1} & a_{\mathfrak{1}} \\
a_{2} & a_{2}
\end{array}\right]+} \\
& {\left[\begin{array}{ll}
b_{1} & b_{\mathrm{P}} \\
b_{2} & b_{2}
\end{array}\right]^{\prime}\left[\begin{array}{ll}
h_{1, t-1} & h_{\mathrm{R}, t-1} \\
h_{\mathbf{1}, t-1} & h_{2, t-1}
\end{array}\right]\left[\begin{array}{ll}
b_{1} & b_{\mathrm{P}} \\
b_{2} & b_{2}
\end{array}\right]}
\end{aligned}
$$

\subsection{Cálculo da efetividade de hedge}

A medida de efetividade de hedge, $E^{*}$, é definida como o percentual de redução da $V a$ Riância do portfólio sintético (LEUTHOLD; JUNKUS; CORDIER, 1989), ou seja:

$$
E^{*}=\frac{\operatorname{Var}(S)-\operatorname{Var}\left(R^{*}\right.}{\operatorname{Var}(S)}=1-\frac{\operatorname{Var}\left(R^{*}\right.}{\operatorname{Var}(S)}
$$

Onde:

$\operatorname{VaR}\left(R^{*}\right)=$ variância do portfólio sintético de risco mínimo, com hedge de variância mínima ou dinâmico

$\operatorname{VaR}(S)=$ variância do portfólio sem hedge

Dessa forma, supondo $X s=1$ e substituindo a Equação 6 na Equação 2, obtém-se a variância do portfólio sintético com posição de hedge ótimo, de variância mínima ou dinâmico:

$$
\operatorname{Var}\left(R *=\mathrm{s}_{s}^{2}-\frac{\mathrm{s}_{f}^{2}}{\mathrm{~s}_{f}^{2}}\right.
$$

Substituindo a Equação 13 na Equação 12:

$$
E^{*}=\frac{\mathrm{s}_{g}^{2}}{\mathrm{~S}_{s^{2}}^{2}{ }_{f}^{2}}
$$

Assim, a Equação 14 aponta a medida de efetividade de hedge, $E^{*}$, que é o próprio coeficiente de determinação ou $R 2$, da regressão expressa pela Equação 7. Dessa maneira, a efetividade de hedge registra a redução da variância do portfólio sintético com posição de hedge como proporção da variância total da posição sem hedge. 
Em suma, calculou-se a efetividade de hedge para portfólios sem hedge, com hedge simples (naïve), hedge estático de variância mínima e hedge dinâmico pelo método GARCH-BEKK.

\subsection{Dados}

Usaram-se as séries de preços semanais de café em US\$/saca de $60 \mathrm{~kg}$ :

i. dos mercados à vista de Mogiana (SP), Paulista (SP), Cerrado (MG), Sul de Minas (MG), Zona da Mata (MG) e Noroeste (PR) (fonte: Insper, 2013). Em adição, formulou-se a amostragem de praças como proxy dos principais mercados das regiões produtoras de café do Brasil de forma não probabilística por conveniência e acessibilidade dos dados de preços;

ii. dos contratos futuros de café da BM\&FBOVESPA (fonte: Insper, 2013).

O período analisado foi de 03 de outubro de 2005 a 24 de setembro de 2012, escolhido de forma não probabilística, por acessibilidade e conveniência. Justifica-se a escolha do período pela acessibilidade dos dados, bem como pela inclusão da crise financeira do subprime em 2008, alterando os níveis e a volatilidade dos preços das commodities (EUROPEAN COMMISSION, 2009). Para ilustrar, registram-se no Quadro 1 as especificações do contrato futuro de café da BM\&FBOVESPA:

Quadro 1 - Especificações dos contratos futuros de café (BM\&BBOVESPA e ICE)

\begin{tabular}{|c|c|}
\hline Especificação & BM\&FBOVESPA \\
\hline Commodity & $\begin{array}{l}\text { Café cru, em grão, de produção brasileira, coffea arabica, tipo } \\
4-25(4 / 5) \text { ou melhor, bebida dura ou melhor, para entrega no } \\
\text { município de São Paulo, SP, Brasil }\end{array}$ \\
\hline Cotação & Dólares dos Estados Unidos por saca de $60 \mathrm{~kg}$ líquidos \\
\hline Unidade de negociação & 100 sacas de 60 kg líquidos ou 6.000 kg líquidos \\
\hline Meses de vencimento & Março, maio, julho, setembro e dezembro \\
\hline Vencimento e último dia de negociação & 60 dia útil anterior ao último dia do mês do vencimento do contrato \\
\hline Local de entrega e preço de referência & $\begin{array}{l}\text { Armazéns credenciados pela BM\&FBOVESPA. No caso de en- } \\
\text { trega em localidade diferente do município de São Paulo (SP), } \\
\text { haverá dedução do custo de frete para apuração do valor de } \\
\text { liquidação }\end{array}$ \\
\hline Liquidação & Entrega física \\
\hline
\end{tabular}

\section{RESULTADOS E DISCUSSÃO}

A seção esquematiza os resultados das pesquisas, empregando o referencial da seção de metodologia e dados.

Na primeira etapa, examinou-se a existência de heterocedasticia dos preços do café em Mogiana (SP), Planalto (SP), Cerrado (MG), Sul de Minas (MG), Zona da Mata (MG) e Noroeste (PR) com o teste de White (1980), com resultados apontados na Tabela 1. 
Tabela 1 - Teste de heterocedasticia de White (1980). Primeira diferença dos preços à vista do café em Mogiana (SP), Planalto (SP), Cerrado (MG), Sul de Minas (MG), Zona da Mata (MG) e Noroeste (PR). Período: 03.10.2005 a 24.09.2012, referência semanal. Em dólares por saca de $60 \mathrm{~kg}$

\begin{tabular}{ccc}
\hline Praça & Estatística & Valor \\
\hline Mogiana (SP) & $\mathrm{R}^{2}$ observado & 8,080489 \\
Planalto (SP) & Prob. Chi-Quadrado(2) & 0176 \\
& $\mathrm{R}^{2}$ observado & 21,78853 \\
Cerrado (MG) & Prob. Chi-Quadrado(2) & 0,0000 \\
& & 7,019176 \\
& $\mathrm{R}^{2}$ observado & 0,0299 \\
Sul de Minas (MG) & Prob. Chi-Quadrado(2) & 9,186655 \\
& $\mathrm{R}^{2}$ observado & 0,0101 \\
Zona da Mata (MG) & Prob. Chi-Quadrado(2) & 14,52679 \\
& $\mathrm{R}^{2}$ observado & 0,0007 \\
Noroeste (PR) & Prob. Chi-Quadrado(2) & 16,92258 \\
& & 0,0002
\end{tabular}

O resultado da Tabela 1 identificou a existência de heterocedasticia nas séries das primeiras diferenças do preço do café em Mogiana (SP), Planalto (SP), Cerrado (MG), Sul de Minas (MG), Zona da Mata (MG) e Noroeste (PR). Dessa forma, usou-se o modelo de hedge dinâmico GARCH-BEKK para calcular as taxas de hedge ótimo semanais. Os parâmetros dos modelos GARCH-BEKK diagonal estão relatados na Tabela 2.

Tabela 2 - Parâmetros do modelo GARCH-BEKK diagonal. Hedge dinâmico do risco de preço do café. Valores em primeiras diferenças dos preços à vista do café em Mogiana (SP), Planalto (SP), Cerrado (MG), Sul de Minas (MG), Zona da Mata (MG), Noroeste (PR) e futuros da BM\&FBOVESPA. Período: 03.10.2005 a 24.09.2012, referência semanal

\begin{tabular}{ccccc}
\hline Praça & & Coeficiente & Erro-padrão & Prob. \\
\hline & $\mathrm{M}(1,1)$ & 1,059651 & 0,389151 & 0,0065 \\
$\mathrm{M}(1,2)$ & 0,752896 & 0,294160 & 0,0105 \\
Planalto & $\mathrm{M}(2,2)$ & 1,094395 & 0,368438 & 0,0030 \\
(SP) & $\mathrm{A} 1(1,1)$ & 0,307312 & 0,039160 & 0,0000 \\
& $\mathrm{~A} 1(2,2)$ & 0,247429 & 0,030842 & 0,0000 \\
& $\mathrm{~B} 1(1,1)$ & 0,939225 & 0,012134 & 0,0000 \\
$\mathrm{~B} 1(2,2)$ & 0,957549 & 0,008676 & 0,0000 \\
& & & & 0.0037 \\
Mogiana & $\mathrm{M}(1,1)$ & 0,903491 & 0,308174 & 0.0049 \\
(SP) & $\mathrm{M}(1,2)$ & 0,755643 & 0,259221 & 0.0088 \\
& $\mathrm{M}(2,2)$ & 1,348767 & 0,458354 & 0,0000 \\
& $\mathrm{~A} 1(1,1)$ & 0,254258 & 0,029827 & 0,0000 \\
& $\mathrm{~A} 1(2,2)$ & 0,269777 & 0,035161 & 0,0000
\end{tabular}




\begin{tabular}{|c|c|c|c|c|}
\hline Praça & & Coeficiente & Erro-padrão & Prob. \\
\hline \multirow{7}{*}{$\begin{array}{c}\text { Cerrado } \\
\text { (MG) }\end{array}$} & $M(1,1)$ & 1.394474 & 0.520001 & 0.0073 \\
\hline & $M(1,2)$ & 0.88926 & 0.311865 & 0.0044 \\
\hline & $M(2,2)$ & 1.106289 & 0.38684 & 0.0042 \\
\hline & $\mathrm{A} 1(1,1)$ & 0.28942 & 0.035096 & 0,0000 \\
\hline & $A 1(2,2)$ & 0.279598 & 0.034306 & 0,0000 \\
\hline & $\mathrm{B} 1(1,1)$ & 0.944192 & 0.012047 & 0,0000 \\
\hline & $\mathrm{B} 1(2,2)$ & 0.946511 & 0.011226 & 0,0000 \\
\hline \multirow{7}{*}{$\begin{array}{l}\text { Sul de Minas } \\
\text { (MG) }\end{array}$} & $M(1,1)$ & 0,839678 & 0,291841 & 0.0038 \\
\hline & $M(1,2)$ & 0,704486 & 0,246839 & 0.0063 \\
\hline & $M(2,2)$ & 1,162753 & 0,439389 & 0.0134 \\
\hline & $\mathrm{A} 1(1,1)$ & 0,286058 & 0,030570 & 0,0000 \\
\hline & $\mathrm{A} 1(2,2)$ & 0,270149 & 0,035006 & 0,0000 \\
\hline & $\mathrm{B} 1(1,1)$ & 0,949223 & 0,008595 & 0,0000 \\
\hline & $\mathrm{B} 1(2,2)$ & 0,952519 & 0,011469 & 0,0000 \\
\hline \multirow{7}{*}{ Zona da Mata (MG) } & $M(1,1)$ & 1,077323 & 0,430854 & 0.0129 \\
\hline & $M(1,2)$ & 0,818973 & 0,342139 & 0.0196 \\
\hline & $M(2,2)$ & 1,214276 & 0,451584 & 0.0133 \\
\hline & $\mathrm{A} 1(1,1)$ & 0,340097 & 0,036953 & 0,0000 \\
\hline & $\mathrm{A} 1(2,2)$ & 0,278345 & 0,035853 & 0,0000 \\
\hline & $\mathrm{B} 1(1,1)$ & 0,929976 & 0,013303 & 0,0000 \\
\hline & $\mathrm{B} 1(2,2)$ & 0,949220 & 0,010780 & 0,0000 \\
\hline \multirow{7}{*}{ Noroeste (PR) } & $M(1,1)$ & 0,846587 & 0,356987 & 0.0183 \\
\hline & $M(1,2)$ & 0,788586 & 0,296874 & 0.0095 \\
\hline & $M(2,2)$ & 1,172123 & 0,372482 & 0.0024 \\
\hline & $\mathrm{A} 1(1,1)$ & 0,366184 & 0,032769 & 0,0000 \\
\hline & $\mathrm{A} 1(2,2)$ & 0,258387 & 0,033706 & 0,0000 \\
\hline & $\mathrm{B} 1(1,1)$ & 0,922800 & 0,011779 & 0,0000 \\
\hline & $\mathrm{B} 1(2,2)$ & 0,954189 & 0,009336 & 0,0000 \\
\hline
\end{tabular}

Fonte: elaborada pelos autores com os dados da pesquisa.

Os resultados da Tabela 2 foram aplicados para calcular as taxas ótimas de hedge dinâmico semanal. Compararam-se as taxas ótimas de hedge dinâmico com as estratégias sem hedge, hedge simples (naïve) e hedge estático, conforme a Tabela 3.

Tabela 3 - Comparação das variâncias semanais e graus de eficiência de estratégias de hedge do risco de preço do café em Mogiana (SP), Planalto (SP), Cerrado (MG), Sul de Minas (MG), Zona da Mata (MG), Noroeste (PR) e futuros da BM\&FBOVESPA. Período: 03.10.2005 a 24.09.2012, referência semanal

\begin{tabular}{cccc}
\hline & Estratégia & Variância semanal & Grau de eficiência \\
\hline & Sem hedge & 37,60 & - \\
Planalto (SP) & Hedge simples & 25,66 & $-31,7 \%$ \\
& Hedge estático & 14,52 & $-61,4 \%$ \\
& Hedge dinâmico & 14,58 & $-61,2 \%$
\end{tabular}




$\begin{array}{cccc} & \text { Sem hedge } & 44,19 & - \\ \text { Mogiana (SP) } & \text { Hedge simples } & 24,54 & -44,5 \% \\ & \text { Hedge estático } & 16,34 & -63,0 \% \\ & \text { Hedge dinâmico } & 16,46 & -62,8 \% \\ \text { Cerrado (MG) } & & - \\ & \text { Sem hedge } & 43,93 & -46,5 \% \\ & \text { Hedge simples } & 23,50 & -64,6 \% \\ & \text { Hedge estático } & 15,57 & -64,6 \% \\ \text { Sul de Minas (MG) } & 15,55 & - \\ & \text { Hedge dinâmico } & & -45,9 \% \\ & \text { Sem hedge } & 43,04 & -64,9 \% \\ & \text { Hedge simples } & 23,27 & -64,0 \% \\ & \text { Hedge estático } & 15,11 & - \\ & \text { Hedge dinâmico } & 15,48 & -35,4 \% \\ & & & -61,1 \% \\ \text { Noroeste (PR) } & \text { Sem hedge } & 39,86 & -60,9 \% \\ & \text { Hedge simples } & 25,77 & - \\ & \text { Hedge estático } & 15,50 & -34,6 \% \\ & \text { Hedge dinâmico } & 15,59 & -64,0 \% \\ & \text { Sem hedge } & & -63,7 \%\end{array}$

Fonte: elaborada pelos autores com os dados da pesquisa.

A seguir, compuseram-se os gráficos comparativos das taxas ótimas de hedge estático e dinâmico em cada região produtora (Figuras 1 a 6).

Figura 1 - Comparativo das taxas ótimas de hedge dinâmico e estático. Valores em primeiras diferenças dos preços à vista do café em Planalto (SP) e futuros da BM\&FBOVESPA. Período: 03.10.2005 a 24.09.2012, referência semanal

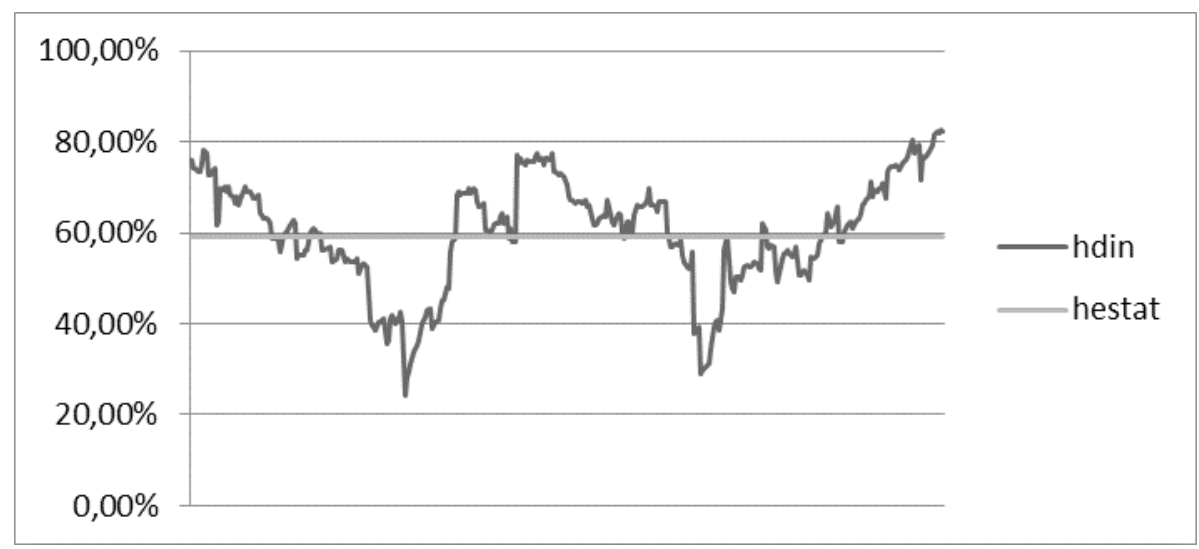

Fonte: elaborada pelos autores com os dados da pesquisa. 
A análise visual da Figura 1 apontou a variação das taxas ótimas de hedge dinâmico dos preços semanais em Planalto (SP), com períodos com diferenças positivas e negativas, dependendo da estrutura dinâmica das covariâncias entre os preços à vista e futuros. No período mais recente, as taxas ótimas de hedge dinâmico foram superiores às do hedge estático, o qual, por hipótese, foi praticado no início do intervalo temporal analisado.

Em adição, pelos dados da Tabela 3, registraram-se diferentes graus de eficiência de estratégias de hedge do risco do preço do café em Planalto (SP) usando contratos futuros da BM\&FBOVESPA. Assim, a estratégia de hedge simples resultou no menor grau de eficiência, enquanto o hedge estático apontou a maior redução da variância semanal, embora muito próxima da redução resultante do hedge dinâmico.

Figura 2 - Comparativo das taxas ótimas de hedge dinâmico e estático. Valores em primeiras diferenças dos preços à vista do café em Mogiana (SP) e futuros da BM\&FBOVESPA. Período: 03.10.2005 a 24.09.2012, referência semanal

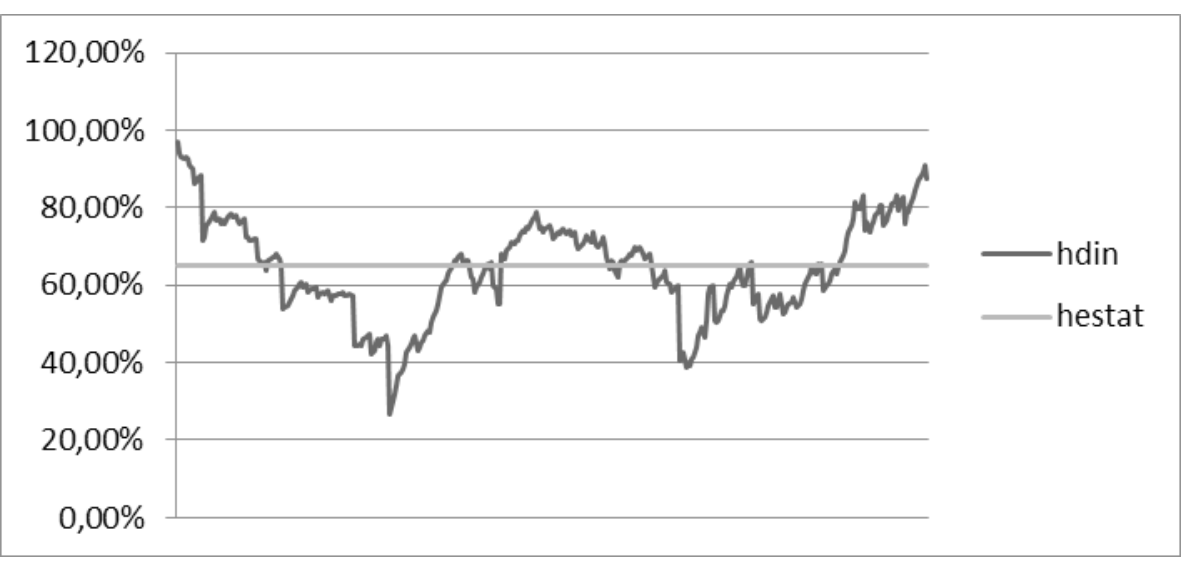

Fonte: elaborada pelos autores com os dados da pesquisa.

A análise visual da Figura 2 apontou a variação das taxas ótimas de hedge dinâmico dos preços semanais em Mogiana (SP), com períodos com diferenças positivas e negativas, dependendo da estrutura dinâmica das covariâncias entre os preços à vista e futuros. No período mais recente, as taxas ótimas de hedge dinâmico foram superiores às do hedge estático, o qual, por hipótese, foi praticado no início do intervalo temporal analisado.

Pelos dados da Tabela 3, registraram-se diferentes graus de eficiência de estratégias de hedge do risco do preço do café em Mogiana (SP) usando contratos futuros da BM\&FBOVESPA. Analogamente ao resultado de Planalto (SP), a estratégia de hedge simples resultou no menor grau de eficiência, enquanto o hedge estático apontou a maior redução da variância semanal, embora muito próxima da redução resultante do hedge dinâmico. 
Figura 3 - Comparativo das taxas ótimas de hedge dinâmico e estático. Valores em primeiras diferenças dos preços à vista do café em Cerrado (MG) e futuros da BM\&FBOVESPA. Período: 03.10.2005 a 24.09.2012, referência semanal

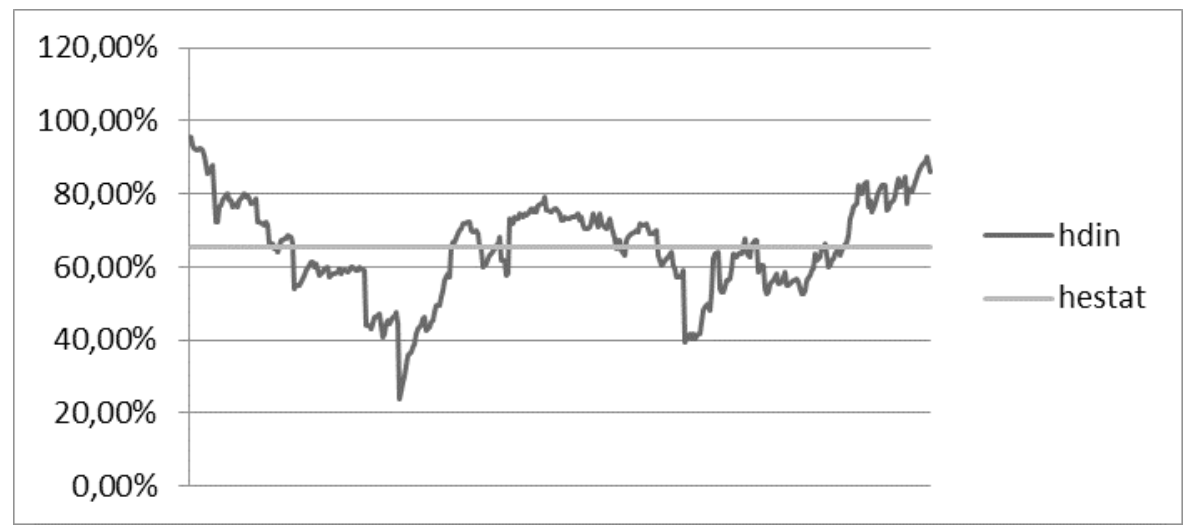

Fonte: elaborada pelo autor com os dados da pesquisa.

A análise visual da Figura 3 apontou a variação das taxas ótimas de hedge dinâmico dos preços semanais em Cerrado (MG), com períodos com diferenças positivas e negativas, dependendo da estrutura dinâmica das covariâncias entre os preços à vista e futuros. No período mais recente, as taxas ótimas de hedge dinâmico foram superiores às do hedge estático, o qual, por hipótese, foi praticado no início do intervalo temporal analisado.

Pelos dados da Tabela 3, registraram-se diferentes graus de eficiência de estratégias de hedge do risco do preço do café em Cerrado (MG) usando contratos futuros da BM\&FBOVESPA.

Analogamente aos resultados de Planalto (SP) e Mogiana (SP), a estratégia de hedge simples resultou no menor grau de eficiência, enquanto o hedge estático apontou a maior redução da variância semanal, embora muito próxima da redução resultante do hedge dinâmico.

Figura 4 - Comparativo das taxas ótimas de hedge dinâmico e estático. Valores em primeiras diferenças dos preços à vista do café em Sul de Minas (MG) e futuros da BM\&FBOVESPA. Período: 03.10.2005 a 24.09.2012, referência semanal

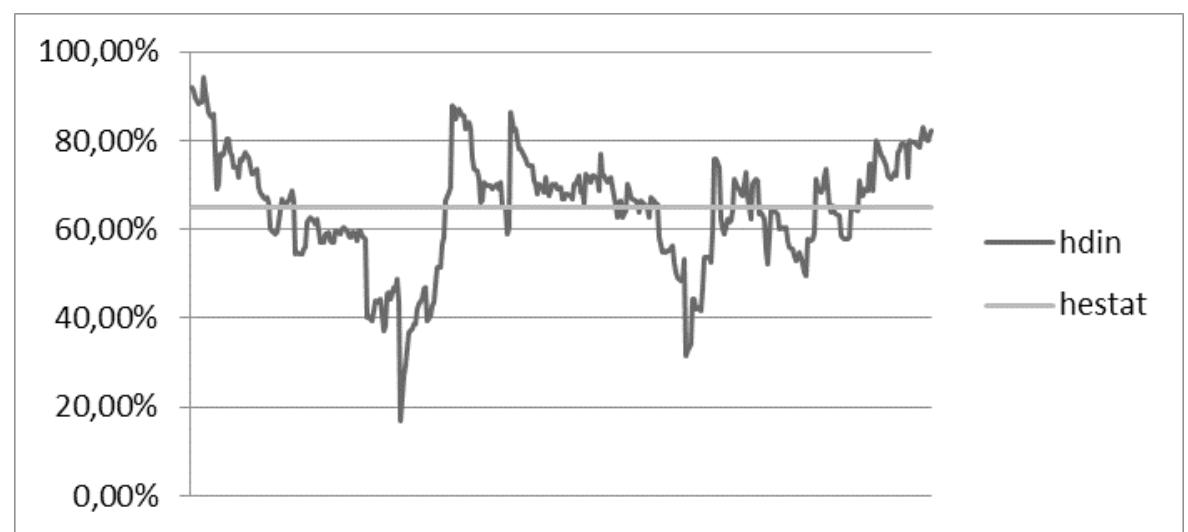

Fonte: elaborada pelos autores com os dados da pesquisa.

A análise visual da Figura 4 apontou a variação das taxas ótimas de hedge dinâmico dos preços semanais em Sul de Minas (MG), com períodos com diferenças positivas e negativas, dependendo da estrutura dinâmica das covariâncias entre os preços à vista e futuros. No período mais recente, as taxas ótimas de hedge dinâmico foram superiores às do hedge estático, o qual, por hipótese, foi praticado no início do intervalo temporal analisado. 
Pelos dados da Tabela 3, registraram-se diferentes graus de eficiência de estratégias de hedge do risco do preço do café em Sul de Minas (MG) usando contratos futuros da BM\&FBOVESPA. Analogamente aos resultados de Planalto (SP), Mogiana (SP) e Cerrado (MG), a estratégia de hedge simples resultou no menor grau de eficiência, enquanto o hedge estático apontou a maior redução da variância semanal, embora muito próxima da redução resultante do hedge dinâmico.

Figura 5 - Comparativo das taxas ótimas de hedge dinâmico e estático. Valores em primeiras diferenças dos preços à vista do café em Zona da Mata (MG) e futuros da BM\&FBOVESPA. Período: 03.10.2005 a 24.09.12, referência semanal

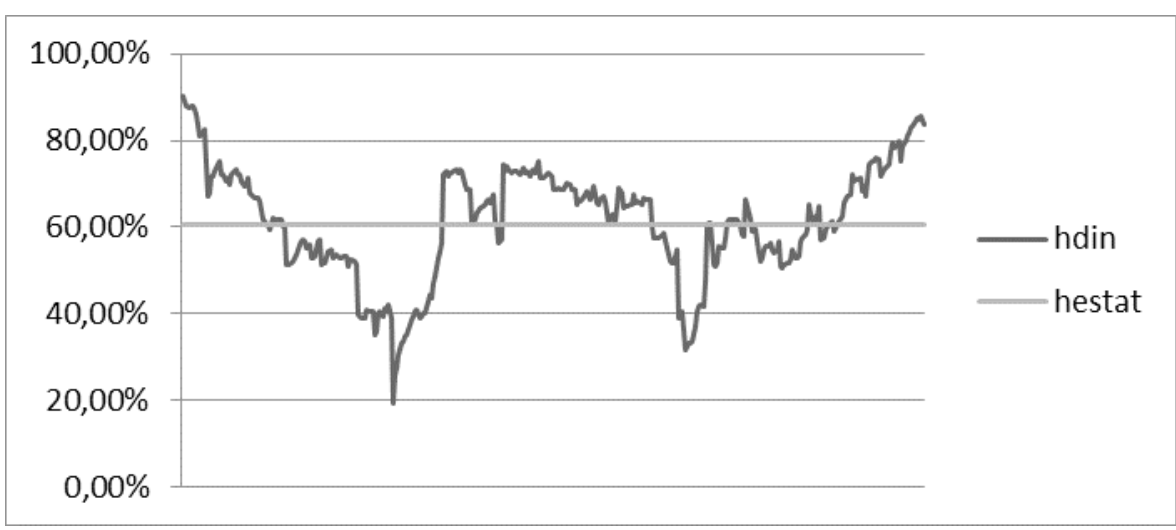

Fonte: elaborada pelos autores com os dados da pesquisa.

A análise visual da Figura 5 apontou a variação das taxas ótimas de hedge dinâmico dos preços semanais em Zona da Mata (MG), com períodos com diferenças positivas e negativas, dependendo da estrutura dinâmica das covariâncias entre os preços à vista e futuros. No período mais recente, as taxas ótimas de hedge dinâmico foram superiores às do hedge estático, o qual, por hipótese, foi praticado no início do intervalo temporal.

Pelos dados da Tabela 3, registraram-se diferentes graus de eficiência de estratégias de hedge do risco do preço do café em Zona da Mata (MG) usando contratos futuros da BM\&FBOVESPA. Analogamente aos resultados de Planalto (SP), Mogiana (SP), Cerrado (MG) e Sul de Minas (MG), a estratégia de hedge simples resultou no menor grau de eficiência, enquanto o hedge estático apontou a maior redução da variância semanal, embora muito próxima da redução resultante do hedge dinâmico.

Figura 6 - Comparativo das taxas ótimas de hedge dinâmico e estático. Valores em primeiras diferenças dos preços à vista do café em Noroeste (PR) e futuros da BM\&FBOVESPA. Período: 03.10.05 a 24.09.2012, referência semanal

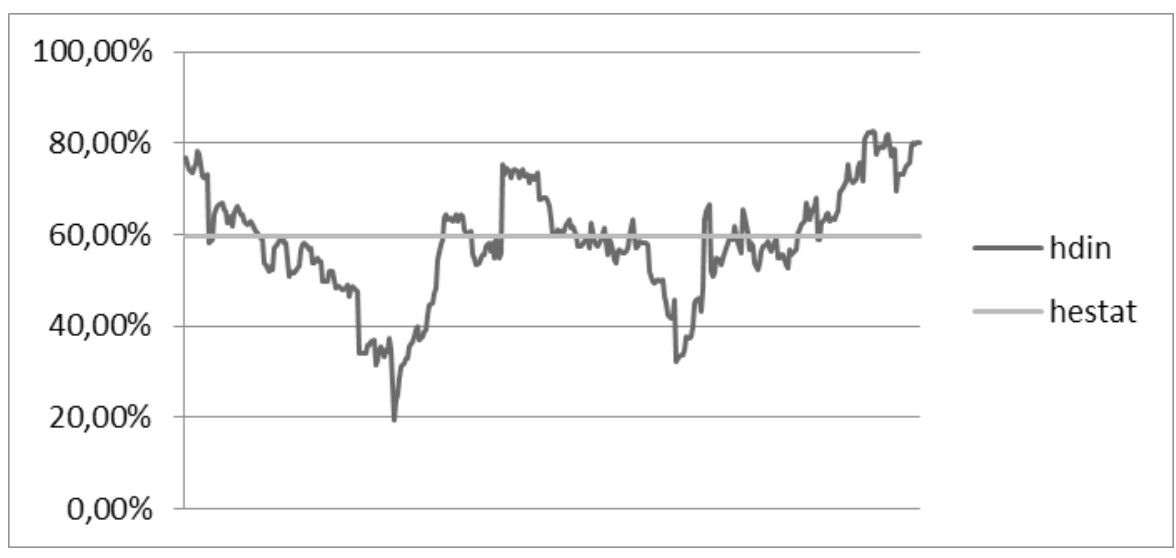

Fonte: elaborada pelos autores com os dados da pesquisa.

A análise visual da Figura 6 apontou a variação das taxas ótimas de hedge dinâmico dos

Rev. AdM. UFSM, SANTA MARIA, v. 10, NÚMERo 5, P. 908-928, 2017 
preços semanais em Noroeste (PR), com períodos com diferenças positivas e negativas, dependendo da estrutura dinâmica das covariâncias entre os preços à vista e futuros. No período mais recente, as taxas ótimas de hedge dinâmico foram superiores às do hedge estático, o qual, por hipótese, foi praticado no início do intervalo temporal analisado.

Pelos dados da Tabela 3, registraram-se diferentes graus de eficiência de estratégias de hedge do risco do preço do café em Noroeste (PR) usando contratos futuros da BM\&FBOVESPA. Analogamente aos resultados de Planalto (SP), Mogiana (SP), Cerrado (MG), Sul de Minas (MG) e Zona da Mata (MG), a estratégia de hedge simples resultou no menor grau de eficiência, enquanto o hedge estático apontou a maior redução da variância semanal, embora muito próxima da redução resultante do hedge dinâmico. Dessa forma, as operações de hedge reduziram o risco de preço semanal, sendo as maiores reduções resultantes da aplicação de modelos quantitativos para calcular as taxas ótimas de hedge.

Além disso, sublinha-se que a vantagem operacional do uso de modelos de hedge dinâmico, comparativamente ao modelo estático, traduz-se em taxas ótimas de hedge ajustadas à trajetória temporal da estrutura de covariâncias, que registrou a ocorrência de heterocedasticia. Por seu turno, o modelo estático supõe que a operação de hedge ocorra em um único ponto no tempo, o que pode não arrolar as necessidades operacionais de gerenciamento de risco de preço dos agentes da cadeia de café do Brasil.

Também, a vantagem da aplicação do hedge dinâmico traduz-se em posições à vista e futuras em linha com a dinâmica da covariância entre os preços à vista e futuros e variância dos preços futuros. Assim, o hedge dinâmico pode reduzir os custos e despesas operacionais. Dessa forma, as operações de hedge reduziram o risco de preço semanal, sendo as maiores reduções resultantes da aplicação de modelos quantitativos para calcular as taxas ótimas de hedge.

Em resumo, os resultados de efetividade superior do hedge dinâmico alinharam-se com pesquisas internacionais e brasileiras. Em particular, registram-se resultados análogos aos de Kroner e Sultan (1993) para portfólios com risco cambial, Bitencourt, Silva e Sáfadi (2006) para o boi gordo no Brasil, Müller (2007) para o café brasileiro e Souza e Caldarelli (2011) para a soja do Brasil.

\section{RESUMO E CONCLUSÕES}

Objetivou-se avaliar a eficiência das estratégias de hedge do risco de preço do café do Brasil nas regiões de Mogiana (SP), Planalto (SP), Cerrado (MG), Sul de Minas (MG), Zona da Mata (MG) e Noroeste (PR), com o uso dos contratos futuros da BM\&FBOVESPA. Assim, calcularam-se as taxas de hedge do risco de preço do café do Brasil com o uso de contratos futuros da BM\&FBOVESPA, aplicando as estratégias sem hedge, hedge simples (naïve), hedge estático e hedge dinâmico. A seguir, compararam-se os resultados para identificar a estratégia de hedge mais eficiente para mitigar o risco.

Assim, objetivou-se avaliar aspectos operacionais de gerenciamento de risco dos preços do café brasileiro usando os contratos futuros domésticos. Os resultados podem ser aplicados em decisões dos agentes da cadeia de oferta de café nas diversas regiões produtoras do Brasil.

Em particular, examinou-se um tema específico, o uso do mercado futuro de café da BM\&FBOVESPA para o gerenciamento de risco de preços. A pesquisa atualizou e particularizou análises de eficiência de estratégias de hedge para o risco de preços do café do Brasil, destacadamente incluindo o novo regime de preços e volatilidade prevalecente após 2008, resultante da crise financeira do subprime.

Dessa forma, compuseram-se estratégias de hedge do risco dos preços regionais de café do país, comparando-se a eficiência de posições sem hedge, com hedge simples (naïve), com hedge ótimo estático e dinâmico GARCH-BEKK. Portanto, apesar dos resultados próximos 
das eficiências das estratégias de hedge ótimo estático e dinâmico, o hedge dinâmico permite calibrar as posições dos portfólios no tempo, resultando em maior eficácia alocativa. $O$ resultado de maior eficiência do hedge dinâmico do risco de preço regional do café do Brasil com contratos futuros da BM\&FBOVESPA alinhou-se com outras pesquisas similares. Entretanto, a diferença foi a atualização do arcabouço analítico examinando o recente regime de preços do café.

Em resumo, os resultados da pesquisa atualizaram um tema relevante para o gerenciamento de risco de preço do café das regiões de Mogiana (SP), Planalto (SP), Cerrado (MG), Sul de Minas (MG), Zona da Mata (MG) e Noroeste (PR), bem como dos contratos futuros da BM\&FBOVESPA. Os resultados podem ser aplicados em decisões dos agentes da cadeia de oferta de café nas diversas regiões produtoras do Brasil. Entretanto, como futura pesquisa, aponta-se a aplicação do arcabouço analítico para outras commodities agropecuárias brasileiras, identificando padrões e estratégias de hedge. Também, outras pesquisas futuras poderiam abordar a análise de sistemas operacionais (trading systems) nos preços futuros agropecuários brasileiros e o uso de hedge bayesiano.

\section{REFERÊNCIAS}

BACHA, E. L. Política brasileira do café. In: Marcellino Martins \& Johnston Exportadores (Ed.). 150 anos de café. Rio de Janeiro: Mergulhar Serviços Editoriais, 1992. p. 15-122.

BAILLIE, R. T.; MYERS, R. J. Bivariate Garch estimation of the optimal commodity futures hedge. Journal of Applied Econometrics, Malden, v. 6, n. 2, pp. 109-124, 1991.

BITENCOURT, W. A.; SILVA, W. S.; SÁFADI, T. Hedge dinâmicos: uma evidência para os contratos futuros brasileiros. Organizações Rurais \& Agroindustriais, Lavras, v. 8, n. 1, p. 71-78, 2006.

BM\&FBOVESPA. Especificações do contrato futuro de café (2012). Disponível em: <http:// www.bmfbovespa.com.br/pt_br/produtos/ listados-a-vista-e-derivativos/commodities/ futuro-de-cafe-arabica-tipo-4-5.htm>. Acesso em: 10 nov. 2013.

BOLLERSLEV, T. Generalized autoregressive conditional heteroskedasticity. Journal of Econometrics, Amsterdã, v. 31, p. 307-327, 1986.

BOOTH, W. C.; COLOMB. G. C.; WILLIAMS, J. $M$. The craft of research. 3. ed. Chicago: The University of Chicago Press, 2008.
CHANG, C. L.; MCALEER, M.; TANSUCHAT, R. Analyzing and forecasting volatility spillovers, asymmetries and hedging in major oil markets. Energy Economics, Amsterdã, v. 32, p. 1.4451.455, 2010.

CHEN, S.; LEE, C.; SHRESTHA, K. Futures hedge ratio: a review. The Quarterly Review of Economics and Finance, Urbana, v. 43, p. 433465, 2003.

COLLINS, R. A. Toward a positive economic theory of hedging. American Journal of Agricultural Economics, Milwaukee, v. 79, n. 2, p. 488-499, 1997.

DELFIM NETTO, A. O problema do café no Brasil. Rio de Janeiro: Instituto Brasileiro do Café, 1973. (Ensaios sobre o Café e Desenvolvimento Econômico).

EDERINGTON, L. H. The hedging performance of the new futures markets. The Journal of Finance, Chicago, v. 34, n. 1, p. 157-170, 1979.

ENGLE, R. GARCH 101: the use of ARCH/GARCH models in applied econometrics. Journal of Economic Perspectives, Pittsburgh, v. 15, n. 4, p. 157-168, 2001.

ENGLE, R. F.; KRONER, K. F. Multivariate simultaneous generalized Arch. Econometric Theory, Cambridge, v. 11, n. 1, p. 122-150, 1995. 
EUROPEAN COMMISSION. Historical price volatility. 2009. Disponível em: <http:// ec.europa.eu/agriculture/analysis/tradepol/ commodityprices/volatility_en.pdf>. Acesso em: 15 jan. 2013.

FILENI, D. H.; MARQUES, P. V.; MACHADO, H. M. $\mathrm{O}$ risco de base e a efetividade do hedge para o agronegócio do café em Minas Gerais. Organizações Rurais e Agroindustriais, Lavras, v. 1, n. 1, p. 42-50, 1999.

GEMECH, F. et al. Market-based pricerisk management: welfare gains for coffee producers from efficient allocation of resources. Oxford Development Studies, Oxford, v. 39, n. 1, p. 49-68, 2011.

HARZER, J. H. et al. Eficiência dos mercados futuros de commodities agrícolas aplicando-se o teste de cointegração. Revista de Administração da UFSM, v. 5, n. 2, p. 336-353, 2012.

INSTITUTO DE ENSINO E PESQUISA (INSPER). Cotações de preços de commodities agropecuárias. 2013.

JOHNSON, L. L. The theory of hedging and speculation in commodity futures. The Review of Economic Studies, Estocolmo, v. 27, n. 3, p. 139-151, 1960.

KARP, L. S. Methods for selecting the optimal dynamic hedge when production is stochastic. American Journal of Agricultural Economics, Milwaukee, v. 69, n. 3, p. 647-657, 1987.

KRONER, K. F.; SULTAN, J. Time-varying distributions and dynamic hedging with foreign currency Futures. The Journal of Financial and Quantitative Analysis, Seattle, v. 28, n. 4, p. 535-551, 1993.

LAZZARINI, D. A. B. A taxa ótima de hedge no mercado brasileiro do boi gordo: uma abordagem com BEKK, DCC e BEKK com dummies de safra e entressafra. 2010. Dissertação (Mestrado em Economia)-Escola de Economia de São Paulo, Fundação Getulio Vargas, São Paulo, 2010.
LEÃO, I. A. et al. Comparativo entre mercados futuros agropecuários internacionais. Revista Ciências Administrativas, v. 19 , n. 1, p. 380402, 2013.

LEUTHOLD, R. M.; JUNKUS, J. C.; CORDIER, J. E. The theory and practice of futures markets. Toronto: Lexington Books: D. C. Heath and Company, 1989.

LIEN, D.; YANG, L Asymmetric effect of basis on dynamic futures hedging: empirical evidence from commodity markets. Journal of Banking \& Finance, Chicago, v. 32, p. 187-198, 2008.

MAIA, F. N. C. S.; AGUIAR, D. R. D. Estratégias de hedge com os contratos futuros de soja da Chicago Board of Trade. Gestão \& Produção, São Carlos, v. 17, n. 3, p. 617-626, 2010.

MARTINS, A. G; AGUIAR, D. R. D. Efetividade do hedge de soja em grão brasileiro com contratos futuros de diferentes vencimentos na Chicago Board of Trade. Revista de Economia e Agronegócio, Viçosa, v. 2, n. 4, p. 449-472, 2004.

MCKENZIE, A. M.; HOLT, M.T. Market efficiency in agricultural futures markets. Applied Economics, Abingdon, v. 34, p. 1.519-1.532, 2002.

MINISTÉRIO DA AGRICULTURA, PECUÁRIA E ABASTECIMENTO (MAPA). Estatísticas de produção e comercialização agropecuária. 2012. Disponível em: <http://www.agricultura. gov.br/acesso-a-informacao/dadosabertos>. Acesso em: 1ㅇ fev. 2014.

MOHAN, S. Market-based price-risk management for coffee producers. Development Policy Review, Malden, v. 25, n. 3, p. 333-354, 2007.

MOSCHINI, G. C.; MYERS, R. J. Testing for constant hedge ratios in commodity markets: a multivariate GARCH approach. Journal of Empirical Finance, Amsterdã, v. 9, p. 589-603, 2002. 
MÜLLER, C. A. S. Análise das estratégias estáticas e dinâmicas de hedge para o mercado brasileiro de café arábica. 132 p. 2007. Tese (Doutorado em Economia Aplicada)-Universidade Federal de Viçosa, Viçosa, 2007. Disponível em: <http://www.ufv. br>. Acesso em: 1ㅇdez. 2013.

MYERS, R. J.; THOMPSON, S. R. Generalized optimal hedge ratio estimation. American Journal of Agricultural Economics, Milwaukee, v. 71, n. 4, p. 858-868, 1989.

NISHIJIMA, M.; SAES, M. S. M.; POSTALI, F. A. S. Análise de concorrência no mercado mundial de café verde. Revista de Economia e Sociologia Rural, Brasília, v. 50, n. 1, p. 69-82, 2012.

OUATTARA, K.; SCHROEDER, T. C.; SORENSON, L. Potential use of futures markets for international marketing of Cote d'Ivoire coffee. The Journal of Futures Markets, Charlottesville, v. 10, n. 2, p. 113-122, 1990.

PIMENTA, M. L. et al. Valores pessoais e percepção de atributos em marcas regionais de café na cidade de Lavras. Revista de Administração da UFSM, v. 4, n. 1, p. 39-52, 2011.

ROSALEM, V.; GOMES, C. S.; OLIVEIRA, M. F. Estratégia de comercialização em mercados derivativos: cálculo de base e risco de base do boi gordo em diversas localidades do Brasil. Revista de Administração da UFSM, v. 1, n. 3, p. 402-417, 2009.

SHI, W.; IRWIN, S. H. Optimal hedging with a subjective view: an empirical Bayesian approach. American Journal of Agricultural Economics, v. 87, n. 4, p. 918-930, 2005.

SILVA, A. R. O.; AGUIAR, D. R. D.; LIMA, J. E. A efetividade do hedge e do cross-hedge de contratos futuros para soja e derivados. Revista de Economia e Sociologia Rural, Brasília, v. 41, n. 2, p. 383-406, 2003. de cross-hedge do bezerro e do hedge do boi gordo no mercado futuro da BM\&F. 106 f. 2002. Dissertação (Mestrado em Economia Aplicada)-Escola Superior de Agricultura Luiz de Queiroz, Universidade de São Paulo, Piracicaba, 2002. Disponível em: <http://bdtd.ibict.br/vufind/Record/ USP_d213dc02ff84bc89a4ed0daa2846d718>. Acesso em: 1으. mar. 2013.

SOUZA, W. A. R. et al. A eficiência de crosshedge do risco de preço de frangos com o uso de contratos futuros de milho da BM\&FBOVESPA. Sociedade, Contabilidade e Gestão, Rio de Janeiro, v. 6, p. 1-15, 2011.

SOUZA, W. A. R.; CALDARELLI, C. E. Análise comparativa da efetividade do hedge para soja usando MQO e o modelo GARCH BEKK bivariado. Revista de Economia, Curitiba, v. 37, p. 1-15, 2011.

SOUZA, W. A. R; MARTINES-FILHO, J. G.; MARQUES, P. V. O hedge simultâneo dos riscos de preço e de câmbio da produção de soja em Rondonópolis (MT), utilizando contratos da BOVESPA-BM\&F. Organizações Rurais \& Agroindustriais, Lavras, v. 13, n. 3, p. 403-413, 2011.

STEIN, J. L. The simultaneous determination of spot and futures prices. The American Economic Review, Pittsburgh, v. 51, n. 5, p. 1.012-1.025, 1961.

\section{UNITED STATES DEPARTMENT OF AGRICULTURE} (USDA). Coffee: world market and trades. Circular series. Dez. 2011. Disponível em: <http://www.fas.usda.gov/psdonline/ circulars/coffee.pdf>. Acesso em: 15 jun. 2013.

WHITE, H. A heteroskedasticity-consistent covariance matrix estimator and a direct test for heteroskedasticity. Econometrica, Malden, v. 48, n. 4, p. 817-838, 1980.

\section{SILVEIRA, R. L. F. Análise das operações}

